\title{
Cerebrospinal fluid pressure during post haemorrhagic ventricular dilatation in newborn infants
}

\author{
A M KAISER AND A G L WHITELAW \\ Department of Paediatrics and Neonatal Medicine, Hammersmith Hospital, London
}

SUMmaRY Post haemorrhagic ventricular dilatation occurs in a minority of newborn infants, but is associated with a high risk of cerebral palsy and developmental delay. Neither the relation of ventricular size to cerebrospinal fluid (CSF) pressure, nor the effect of CSF removal on prognosis, have been established. Normal CSF pressure measured at subarachnoid cannulation was mean (SD) $2.8(1.4) \mathrm{mm} \mathrm{Hg}$. Values were significantly higher in post haemorrhagic ventricular dilatation-9.1 (3.7) $\mathrm{mm} \mathrm{Hg}$ when the ventricles were expanding, and $4.5(2.4) \mathrm{mm}$ $\mathrm{Hg}$ when they were static or contracting. No significant relation between head circumference and CSF pressure was found in this series. Raised CSF pressure is associated with progressive ventricular dilatation, and may contribute to the increased risk of neurological abnormality.

Cerebral periventricular haemorrhage occurs in about $40 \%$ of infants with birthweights below $1500 \mathrm{~g},{ }^{12}$ and also less commonly in infants of greater weight. When it is followed by persistent or progressive ventricular dilatation, the neurodevelopmental prognosis is substantially worse..$^{2-4}$ Stewart $e t$ $a l^{4}$ found that $45 \%$ of survivors with post haemorrhagic ventricular dilatation had serious impairment from cerebral palsy, developmental delay (developmental quotient $<70$ ), or sensorineural deafness. It may be hypothesised that these infants have aggravated neurological damage resulting from a period of raised intracranial pressure. This is known to cause periventricular oedema, ${ }^{5}$ distortion of developing neural pathways, ${ }^{6}$ and may cause decreased cerebral perfusion.

Several authors have established that intracranial pressure is raised in post haemorrhagic ventricular dilatation, ${ }^{7-12}$ even in so called 'normal pressure hydrocephalus, ${ }^{10}$ during progression of dilatation. In most of these reports, however, ${ }^{7-10}$ anterior fontanelle pressure was measured, an unreliable reflection of intracranial pressure. ${ }^{1314}$ Intracranial pressure measured directly (by ventricular catheter $)^{11} 12$ was raised in four of seven infants, although the exact aetiology of the hydrocephalus in all cases was unclear. In only one report ${ }^{10}$ was the course of the dilatation shown by serial computed tomography or ultrasound scans, and changes in pressure related to it.
We have investigated the course of post haemorrhagic ventricular dilatation by direct, serial measurement of cerebrospinal fluid (CSF) pressure, ventricular size, and head circumference in order to elucidate their relation. The CSF pressure was also compared with that in normal controls.

\section{Methods}

Subjects. From November 1981 to May 1984 there were 828 admissions to this neonatal intensive care unit, and 140 of them (16.9\%) suffered periventricular haemorrhage. Seventeen of these $(12 \cdot 1 \%)$ were complicated by ventricular dilatation $(2 \cdot 1 \%$ incidence). Three further infants were referred with the established condition. The study group comprised the 16 of these 20 infants in whom CSF pressure was measured.

Clinical details of the study group are shown in the Table. They were grouped according to the outcome of the dilatation. The progressive group comprised the eight babies whose ventricular size increased for 2 to 10 weeks, terminated by death (two cases) or surgical CSF shunting (six cases). The transient group comprised the six babies whose ventricular size decreased to normal after 2 to 6 weeks of appropriate management for ventricular dilatation. The static group comprised the two babies in whom an initial acute increase in ventricular size was succeeded by growth at a normal rate. 
Table Patient data

\begin{tabular}{|c|c|c|c|c|}
\hline Birthweight $(g)$ & Gestation (wks) & Clinical details & No of LPs/VTs & $\begin{array}{l}\text { Outcome of } \\
\text { dilatation }\end{array}$ \\
\hline 1380 & 29 & RDS, asphyxia, jaundice & $1 / 3$ & Progressive \\
\hline 2200 & 32 & RDS, IPPV, PT, fits & $3 / 0$ & Transient \\
\hline 2000 & 31 & RDS, IPPV. jaundice, PDA & $1 / 0$ & Transient \\
\hline 2870 & 38 & MTM, IPPV, PT, & $2 / 0$ & Static \\
\hline 1640 & 32 & MTM, IPPV. PT, jaundice & $5 / 0$ & Progressive (died) \\
\hline 1410 & 31 & RDS. IPPV, IADH, & $7 / 0$ & Progressive \\
\hline 830 & 28 & RDS, IPPV, PDA, septicacmia & $3 / 0$ & Transient \\
\hline 2600 & 34 & Dysrhythmias, jaundice & $1 / 0$ & Transient \\
\hline 2600 & 37 & Factor $\mathrm{V}$ deficiency & $1 / 1$ & Progressive \\
\hline 1070 & 28 & RDS, IPPV, jaundice, PDA & $7 / 18$ & Progressive (died) \\
\hline 1190 & 28 & RDS, IPPV. PT, PDA & $4 / 9$ & Transient \\
\hline 1320 & 28 & RDS, IPPV, PT, PDA & $3 / 0$ & Transient \\
\hline 940 & 26 & RDS, IPPV, PT, & $1 / 6$ & Progressive \\
\hline 2670 & 38 & Polycythacmia, fits & $7 / 3$ & Progressive \\
\hline 1450 & 28 & RDS, IPPV, PHT, & $4 / 0$ & Static \\
\hline 680 & 26 & RDS, IPPV, jaundice, fits, PDA & $0 / 4$ & Progressive \\
\hline
\end{tabular}

RDS = respiratory distress syndrome

IPPV $=$ intermittent positive pressure ventilation

$\mathrm{PT}=$ pneumothorax/thoraces

$\mathrm{PDA}=$ patent ductus arteriosus

\author{
MTM = myotubular myopathy \\ IADH = inappropriate ADH secretion \\ PHT= pulmonary hypertension \\ $\mathrm{LP}=$ lumbar punctures \\ $\mathrm{VT}=$ ventricular tap
}

Ultrasonography. In accordance with existing protocols for prospective studies of infant neurology in this unit, all babies underwent cranial ultrasonography by ATL Mechanical Sector Scanner within 24 hours of hospital admission. Infants who were ill or of less than 28 weeks' gestation were scanned daily for one week, then twice weekly until discharge from hospital. The remaining babies were scanned weekly until discharge. With this thoroughness of scanning, it is unlikely that any cases were missed.

In infants with periventricular haemorrhage, the width of each lateral ventricle, horizontally from the midline to its lateralmost extent, was measured in the transfontanelle coronal view just posterior to the interventricular foramina. Each scan and measurement was checked immediately until repeated measurements agreed to within $1 \mathrm{~mm}$. The calipers were calibrated electronically before each baby was scanned. Ventricular dilatation was diagnosed when the width exceeded the 97 th centile of Levene ${ }^{15}$ by at least $4 \mathrm{~mm}$ on two consecutive occasions. If there was asymmetrical dilatation of the two ventricles, the smaller measurement was taken. Scans of study infants were repeated daily until they and the baby were stable, and then every two or three days until discharge.

Head growth. Occipitofrontal circumference was measured using an inelastic tape measure. Rates of head growth were compared with the centiles of Gairdner and Pearson. ${ }^{16}$
Cerebrospinal fluid pressure measurements. Pressure was measured directly by a Gaeltec pressure transducer (Gaeltec, Scotland) attached to a needle inserted into the subarachnoid space or lateral ventricles. This was attempted whenever CSF removal was clinically indicated (to exclude meningitis, to measure protein or blood content, or to remove CSF therapeutically as approved by Hammersmith Hospital Ethics Committee). Lumbar puncture was attempted first, then ventricular puncture if CSF flow was inadequate (as in 44 out of 94 instances, $47 \%$ ). The infant lay horizontally during the procedure, his head and neck in line with his trunk. The pressure was recorded when the infant was at rest, with the transducer held level with the right atrium.

To ensure that the measurement truly reflected CSF pressure, we imposed several acceptance criteria-that the flow of CSF be ready both before and after the measurement, that bloody taps be due to truly bloody CSF and not to venous cannulation, and that the pressure wave displayed on the monitor should fluctuate with cardiac and respiratory cycles and show a positive Queckenstedt's test. Since it is generally accepted that pressure is evenly transmitted throughout the neonatal cranial cavity, and that there is no anatomical valve between the cranial and spinal subarachnoid spaces, we believe that these CSF pressure values also reflected the intracranial pressure. We have confirmed this by finding less than $1 \mathrm{~mm} \mathrm{Hg}$ difference in a few babies undergoing simultaneous ventricular and lumbar measurements. 
In this way, we performed $94 \mathrm{CSF}$ pressure estimations in the study group (mean 5.3 per patient, range 1 to 25 ). It was also measured when 43 neurologically and structurally normal neonates underwent 55 lumbar punctures during septic screens performed because of apnoea, fever, bradycardia, single fits, or positive blood cultures. Although some of these signs may be accompanied by acutely raised intracranial pressure, at the time of pressure estimation they had ceased, so it was unlikely that intracranial pressure was raised. Hence we considered these babies to constitute a normal control population.

There were no complications from CSF pressure measurement in the short or longer terms.

\section{Results}

Cerebrospinal fluid pressure in the control infants was mean (SD) $2.8(1.4) \mathrm{mm} \mathrm{Hg}$. The upper limit of normal range (mean $+2 \mathrm{SD}$ ) was $5.7 \mathrm{~mm} \mathrm{Hg}$. There was no variation with birthweight or current weight, or with gestational or chronological age.

The typical course of an infant with post haemorrhagic ventricular dilatation is given in Fig. 1. This girl, the second of twins of 28 weeks' gestation, whose birthweight was $1190 \mathrm{~g}$, was transferred to our unit on the second day of life with respiratory distress syndrome requiring ventilation. Her course was complicated by pneumothorax and patent duc-
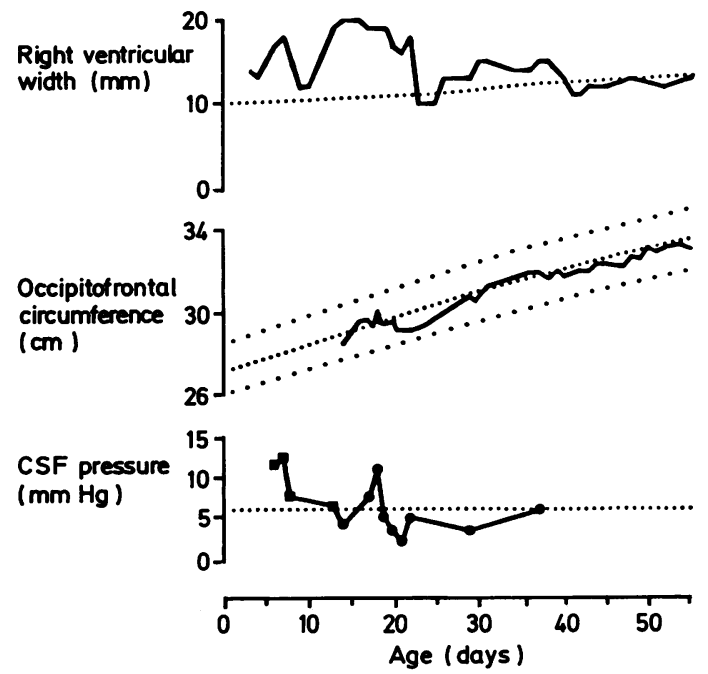

Fig. 1 Course of infant with 'transient' dilatation (see text for explanation).

Dotted lines represent normal values, as explained in text. Squares=lumbar CSF pressure. Circles $=$ ventricular CSF pressure. tus arteriosus. Periventricular haemorrhage was present on admission and progressed to grade III $^{17}$ with unilateral parenchymal extension, and then to transient ventricular dilatation. Figure 1 displays the size of the right ventricle (compared with Levene's 97th centile), the occipitofrontal circumference (compared with Gairdner and Pearson's centiles), and the $13 \mathrm{CSF}$ pressures (compared with our upper limit of normal). The four lumbar punctures are denoted by squares, and the nine ventricular taps by circles; all were performed for therapeutic removal of CSF.

Figure 2 shows the CSF pressures in two groups of infants, divided according to the outcome of the ventricular dilatation. Group A comprises all those measurements in infants with static dilatation, with transient dilatation during the contraction phase, and with initially progressive dilatation after effective surgical CSF shunting. Group B constitutes all measurements in infants with progressive dilatation before CSF shunting, and with transient dilatation during the expansion phase. There are 67 pressure measurements in group $\mathrm{A}$, with mean

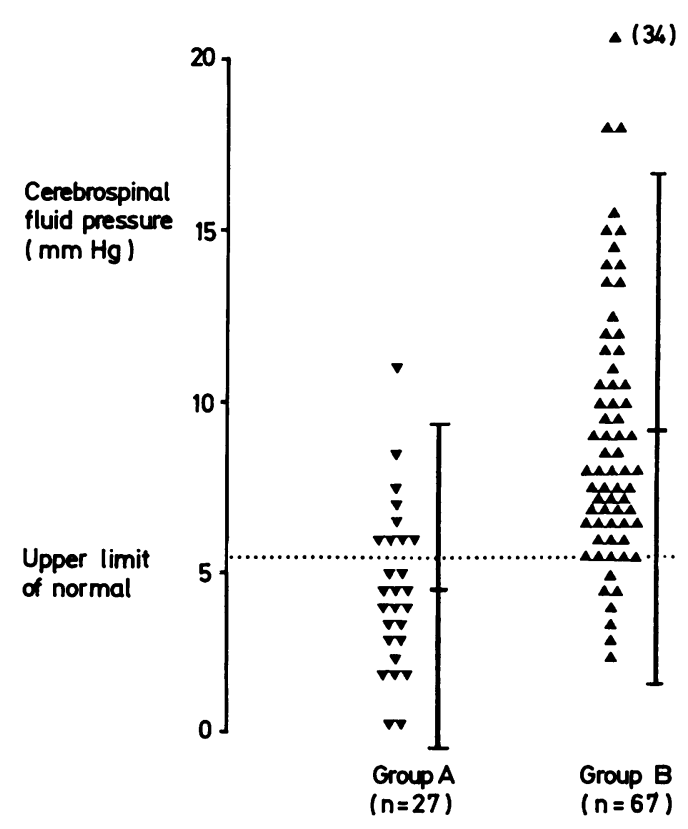

Fig. 2 Cerebrospinal fluid pressure values according to type of ventricular dilatation.

Vertical bars represent mean (SD).

Group A: during static, contracting transient, or adequately shunted dilata tion, $\mathrm{n}=27$, mean (SD) $4.5(2.4) \mathrm{mm} \mathrm{Hg}$.

Group $B$ : during progressive or expanding transient dilatation, $n=67$, mean (SD) 9.1 (3.7) $\mathrm{mm} \mathrm{Hg}$.

Group $A$ and $B$ differ significantly $(t=5.9, d f=92, P<0.001)$. 
(SD) $4.5(2.4) \mathrm{mm} \mathrm{Hg}$. In group B there are 27 measurements, with mean (SD) $9 \cdot 1(3 \cdot 7) \mathrm{mm} \mathrm{Hg}$. These differ significantly by Student's unrelated $t$ test $(\mathrm{t}=5 \cdot 9, \mathrm{df}=92, \mathrm{P}<0 \cdot 001)$. They also both differ significantly from the control values (respectively, $\mathrm{t}=4.0$ and $11 \cdot 7, \mathrm{df}=79$ and $119, \mathrm{P}<0.001)$. The linear regression coefficient of increment in ventricular width on CSF pressure was $+0 \cdot 30$ $(\mathrm{P}<0 \cdot 05)$.

When the pressure measurements were divided into groups corresponding to phases of occipitofrontal circumference change faster than, parallel to, or slower than the centiles, no significant difference between the mean pressures was found.

\section{Discussion}

We have shown that in neonates with ventricular dilatation after periventricular haemorrhage, CSF pressure is higher in the group of patients with a progressive increase in ventricular size than in that with a decrease in size, and that there is a positive correlation between increases in ventricular size and CSF pressure. Mean CSF pressure in the former group was about three times as high as control values.

Our failure to show a significant relation between head growth and CSF pressure corroborates other work, 18 and is probably due to the buffering effect of CSF displacement from the cranial subarachnoid space into the venous system, ${ }^{19}$ or to the variable pathogenesis of post haemorrhagic ventricular dilatation.

We realise that the pathogenesis of the ventricular dilatation differs widely between babies. The two chief processes are obstruction of CSF outflow, causing 'pressure driven' dilatation, and loss of brain parenchyma with passive expansion of the CSF space to fill the gap. In the former situation, CSF pressure will be raised while dilatation occurs, and the neurological outcome may be related to this. In the latter, CSF pressure will be normal, and the neurological outcome related to the site and extent of the parenchymal damage. We would expect the relation of ventricular size to CSF pressure to hold mainly in the former group. Because we were often unable to distinguish the pathogenesis (from indicators such as the shape of the ventricles and their rate of growth compared with head growth) in a given baby we included all babies in the analysis.

Although the extremely high intracranial pressure of older children and adults $(25 \text { to } 35 \mathrm{~mm} \mathrm{Hg})^{20}$ with intracranial lesions is prevented by the open fontanelles and sutures of the neonatal skull, nevertheless the raised CSF pressure of some babies with post haemorrhagic ventricular dilatation may have adverse effects such as periventricular oedema, distortion of neural pathways, and possibly impaired perfusion in watershed areas of the brain. This may contribute to their poor neurological outcome.

If it is decided to reduce CSF pressure by repeated lumbar puncture or ventricular shunt operation, it would seem logical to achieve and maintain the pressure within the range found in control neonates (upper limit of normal $5.7 \mathrm{~mm} \mathrm{Hg}$ ). Standardised CSF pressure measurement may be useful in monitoring this treatment. With effective return to normal of CSF pressure, the poor prognosis of post haemorrhagic ventricular dilatation may be improved.

We wish to acknowledge the help of Dr F M C Besag with CSF pressure measurements; Drs M I Levene, L DeVries, and L M S Dubowitz with ultrasound scanning; and all medical and nursing members of the staff of Hammersmith Hospital Neonatal Unit for tolerance, help, and advice. Mr J Messeguer rendered technical assistance. AMK is supported by Birthright.

\section{References}

I Levene MI, Wigglesworth JS, Dubowitz V. Cerebral structure and intraventricular haemorrhage in the neonate: a real-time ultrasound study. Arch Dis Child 1981;56:416-24.

2 Krishnamoorthy KS, Shannon DC, DeLong GR, Todres ID, Davis KR. Neurologic sequ_lae in the survivors of neonatal intraventricular hemorrhage. Pediatrics 1979;64:233-7.

3 Palmer P. Dubowitz LMS, Levene MI, Dubowitz V. Developmental and neurological progress of preterm infants with intraventricular haemorrhage and ventricular dilatation. Arch Dis Child 1982;57:748-53.

4 Stewart AL, Thorburn RJ, Hope PL, Goldsmith M, Lipscomb AP, Reynolds EOR. Ultrasound appearance of the brain in very preterm infants and neurodevelopmental outcome at 18 months of age. Arch Dis Child 1983;58:598-604.

${ }^{5}$ Weller RO, Shulman K. Infantile hydrocephalus: clinical, histological, and ultrastructural study of brain damage. J Neurosurg 1972;36:255-65.

- Plets C. De invloed van de experimentele hydrocefalie op de cerebrale bloedverzerging. Leuven: Acco, 1977.

7 Davidoff LM, Chamlin M. The 'Fontanometer'. Pediatrics 1959;24:1065-8

${ }^{*}$ Vidyasagar D, Raju TNK. A simple noninvasive technique of measuring intracranial pressure in the newborn. Pediatrics 1977;59 Suppl:957-61

9 Vidyasagar D, Raju TNK, Chiang J. Clinical significance of monitoring anterior fontanel pressure in sick neonates and infants. Pediatrics 1978;62:996-9.

10 Hill A, Volpe JJ. Normal pressure hydrocephalus in the newborn. Pediatrics 1981;68:623-9.

11 Hayden PW, Shurtleff DB, Foltz EL. Ventricular fluid pressure recordings in hydrocephalic patients. Arch Neurol 1970;23: 147-54.

12 McCullough DC. A critical evaluation of continuous intracranial pressure monitoring in pediatric hydrocephalus. Childs Brain 1980;6:225-41.

13 Horbar JD, Yeager S, Philip AGS, Lucey JF. Effect of application force on noninvasive measurements of intracranial pressure. Pediatrics 1980;66:455-7.

14 Kaiser AM, Whitelaw AGL, Besag FMC. An evaluation of fontanelle pressure measurements. In: Rolfe P, ed. Foetal and neonatal physiological measurements. London: Butterworths. (In press). 
15 Levene MI. Measurement of the growth of the lateral ventricles in preterm infants with real-time ultrasound. Arch Dis Child 1981;56:900-4.

16 Gairdner D, Pearson J. A growth chart for premature and other infants. Arch Dis Child 1971;46:783-7.

17 Levene MI, Fawer C-L, Lamont RF. Risk factors in the development of intraventricular hacmorrhage in the preterm neonate. Arch Dis Child 1982:57:410-7.

${ }^{18}$ Korobkin R. The relationship between head circumference and the development of communicating hydrocephalus in infants following intraventricular hemorrhage. Pediatrics 1975;56:74-7.
${ }^{19}$ Pape KE, Wigglesworth JS. Haemorrhage, ischaemia and the perinatal brain. London: William Heinemann Medical, 1979:123-4.

20) Bruce DA, Berman WA, Schut L. Cerebrospinal fluid pressure monitoring in children: physiology, pathology and clinical usefulness. Adv Pediatr 1977:24:233-90.

Correspondence to Dr A G L Whitelaw, Department of Paediatrics, Hammersmith Hospital, Ducane Road, London W12 0HS.

Received 29 April 1985

\section{One hundred years ago}

\section{'Sleeplessness in an infant'}

The Lancet, October 31 and November 14, $1885: 838$ and 933

\section{'To the Editor of The Lancet'}

'SIR, - I should be glad if any of your numerous readers would give me their opinion on the following case.

I am attending an infant six months old, hand-reared. He is a very fine boy, is well developed, has already got six teeth without the slightest trouble, and has the appearance of a child about twelve months old. But here comes the difficulty. He seldom sleeps at night, and very little in the daytime. He does not seem to suffer any pain, and gains flesh. He is well cared for; but he wearies his nurse night and day by preventing her from sleeping. So serious is it for her that I have advised the parents to provide a special night nurse for the child. I have given small doses of bromide of potassium with tincture of hyoscyamus, then with succus conii, and now and then chloral. They seem to relieve him; but, notwithstanding, he seldom sleeps. Will anybody suggest a line of treatment, or recommend me any standard authority whereby I might glean some further information? I might mention that the child is very excitable, good-tempered, and exceedingly lively, and it is amazing how well he looks under the circumstances.

Oct. 27th,1885.

I am, Sir, yours faithfully, 'SUBSCRIBER.'

'SIR, - With reference to the case for which "Subscriber" invites suggestions in your issue of the 31st ult., let me strongly advise a discontinuance of all sedatives, especially chloral, as recommended by Dr. Illingworth, and to give a course of cod-liver oil. The child is evidently growing and developing beyond its nerve-power-growing beyond its strength; hence nervous wakefulness. Give the child the following mixture:-Castor oil, $\xi_{\text {iss; }}$ syrup, $\boldsymbol{\zeta}_{i}$.; syrup of saffron, $\xi_{\text {ss. }}$ One teaspoonful four, five, or six times a day. I shall be glad to hear from "Subscriber." I am, Sir, yours obediently, 